\title{
Photostability studies on gemifloxacin and lomefloxacin in bulk powder and dosage forms
}

\author{
Marwa Hosny Tammam \\ Drug Bioavailability Center, National Organization for Drug Control and Research (NODCAR), Giza, 35521, Egypt \\ *Corresponding author at: Drug Bioavailability Center, National Organization for Drug Control and Research (NODCAR), Giza, 35521, Egypt. \\ Tel.: +2.011.12289346. Fax:+2.02.33379445. E-mail address: tammam.marwa@gmail.com (M.H. Tammam).
}

\section{ARTICLE INFORMATION}

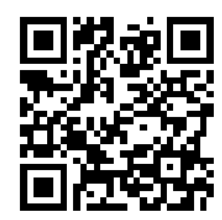

DOI: $10.5155 /$ eurjchem.5.1.73-80.884

Received: 24 July 2013

Received in revised form: 18 August 2013

Accepted: 18 August 2013

Online: 31 March 2014

\section{KEYWORDS}

\section{HPLC}

LC-MS/MS

Gemifloxacin

Lomefloxacin

Photostability

Fluoroquinolone drugs

\section{Introduction}

Drug photostability constitutes an important current subject of investigation as the photodegradation process can result in a loss of the potency of drug and also may cause adverse effects due to the formation of toxic degradation products [1-5].

As a consequence, various pharmacopoeias prescribe light protection for a number of drugs and adjuvants during storage. Knowledge of the photochemical and photophysical properties of drugs is essential to ensure adequate product quality and also for predicting drug phototoxicity. To this end, specific guidelines for the phototoxicity testing on drugs have been proposed by the International Conference on Harmonization (ICH) [1]. Some classes of drugs have been investigated thoroughly for their photostability and phototoxicity [1,6-8]. Studies of most fluoroquinolones (FQs) developed in the past have reported that they cause phototoxicity with various degrees of severity [9].

Derivatives of this class of drugs containing a halogen atom at position 8 were found to have the greatest phototoxic properties. Lomefloxacin, sparfloxacin, fleroxacin, and clinafloxacin are included in this group of FQs. On the other hand, a hydrogen group at position 8 provides a FQ molecule with only a mildly phototoxic potential [9-12]. UV irradiation of 8-halogenoquinolones has been reported to cause photo- instability [13-16]. FQ derivatives with a methoxy group at position 8 , such as gatifloxacin and moxifloxacin, have been demonstrated to be the most photostable and the least phototoxic [1]. Knowledge about the photostability of drug substances and drug products is thus also important to provide information in the handling, packaging and labelling of drug products [1,17]

Gemifloxacin mesylate (7-[(4Z)-3-(aminomethyl)-4methoxyimino-pyrrolidin-1-yl]-1-cyclopropyl-6-fluoro-4-oxo1,8-aphthyridine-3-carboxylic acid [18] (Figure 1) and lomefloxacin $(R S)$-1-ethyl-6,8-difluoro-7-(3-methyl piperazin1-yl)-4-oxo-quinoline-3-carboxylic acid [18] (Figure 2) are antibacterial agents. They have a broad antibacterial spectrum.Consequently, they are clinically used as the antibiotics of first choice for general bacterial infectious diseases and their efficacies are highly appreciated [19].

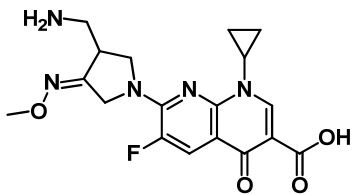

Figure 1. Chemical structures of gemifloxacin, 7-[(4Z)-3-(aminomethyl)- 4methoxyimino-pyrrolidin-1-yl]-1-cyclopropyl-6-fluoro-4-oxo-1,8naphthyridine-3-carboxylic acid. 


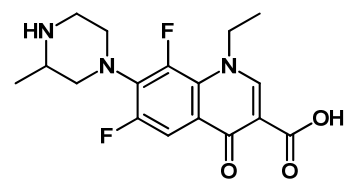

Figure 2. Chemical structures of lomefloxacin, $(R S)$-1-Ethyl-6,8-difluoro- 7(3-methylpiperazin-1-yl)- 4-oxo-quinoline-3-carboxylic acid.

The present study deals with the photostability of GFLX and LFLX under a combination of a near UV fluorescent lamp and a cool white fluorescent lamp (option 2). In addition, this study clarifies the effect of $\mathrm{TiO}_{2}$ addition on the photostability of these drugs in their aqueous solutions. The photo decomposition of these drugs was monitored by UV spectrophotometric method, HPLC and LC-MS/MS.

\section{Experimental}

\subsection{Chemicals and reagents}

GFLX (99.9\%) and Factive tablets were kindly supplied by Hikma Pharma S.A.E. (Egypt). LFLX (99.8\%) and MaxaFloxtablets were kindly supplied by Pharaoina Co., (Egypt). LCMS grade acetonitrile and formic acid were purchased from (EMerck, Darmstadt, Germany). Citric acid and sodium citrate were purchased from (Finechem, Egypt). Titanium dioxide was purchased from Qualikems (New Delhi, India). Water was obtained from a Milli-Q water purification system (Millipore Co, France). The mobile phase component was filtered through a $0.45 \mu \mathrm{m}$ Whatman membrane filter prior to its use.

\subsection{Instruments and chromatographic conditions}

CLIMACELL chamber (MMM group, Germany) was used as a photostability testing device). It is equipped with a microprocessor-controlled system of humidification and dehumidification with a powerful lighting system that guarantees excellent homogenous parameters for testing (near UV light fluorescent lamp and cool white fluorescent lamp). Working temperature used ranged from 0.0 up to $99.9{ }^{\circ} \mathrm{C}$ (without humidity) and from 10 to $90.0{ }^{\circ} \mathrm{C}$ (with humidity). Inner glass door and inner chamber is made of stainless steel DIN 1.4301 (AISI 304). It contains a shelf for putting samples and a sensor for irradiance measurements.

Absorption spectra were measured on Shimadzu UV-VIS spectrophotometer from Helios Company. It is a double beam spectrophotometer with two matched $1 \mathrm{~cm}$ quartz cells, connected to an IBM compatible personal computer (PC) and a HP-600 inkjet printer.

Analysis for drug solutions before and after illumination was performed on high performance liquid chromatographic system (Waters, Milford, USA) equipped with pump controlled by Waters 610 controller, Waters 717 auto sampler injector, Waters 486 variable wavelength UV detector. For the data acquisition and integration Waters Empower software operated by Pentium III (450MHz) processor (Lenovo, UK) was used. The analytical column employed was Thermo $\mathrm{C}_{18}$ column $(150 \times 4.6 \mathrm{~mm}$, id).The mobile phase consisted of a mixture of citrate buffer $(\mathrm{pH}=2.5)$ and acetonitrile $(70: 30, v: v)$ The mobile phase was freshly prepared and was filtered before use. All separations were performed isocratically at a flow rate of $1.5 \mathrm{~mL} / \mathrm{min}$ and column condition was maintained at ambient temperature. Peaks were monitored by UV detector adjusted at $270 \mathrm{~nm}$.

Separation and detection for photodegradation products were performed on Agilent Triple quadrupoles mass spectrometer with API source coupled with Agilent pump controlled by Agilent 1200 controller and equipped with Agilent 1200 auto sampler injector. For the data acquisition and integration, Agilent MassHunter software operated by Pentium III (450 MHz) processor (HP, USA). Agilent SB-C18 $(50 \times 4.6 \mathrm{~mm}), 1.8 \mu \mathrm{m}$ particle size column was used for separation of photodegradation peaks using acetonitrile: $0.1 \%$ formic acid $(84: 16, v: v)$ as mobile phase with flow rate was 0.6 $\mathrm{mL} / \mathrm{min}$.

\subsection{Sample preparation and irradiation}

The tested GFLX and LFLX samples were prepared as follows: Stock solutions of concentration $1 \times 10^{-3} \mathrm{M}$ of GFLX and LFLX were prepared in double distilled water. Working standard solutions of $1 \times 10^{-5} \mathrm{M}$ of GFLX and LFLX were prepared by appropriate dilution from the corresponding stock solution in double distilled water. The drug solution was placed into quartz cuvette with stopper and measured using spectrophotometry as a reference (zero time) then placed in the chamber for different periods of time followed by spectroscopic analysis and compared with control samples of the drug which covered with an aluminium foil placed in the chamber for the same periods of time.

GFLX and LFLX market tablets were extracted, purified and prepared in double distilled water in the same concentration as their corresponding drugs. Their spectra were measured before and after illumination. The effect of titanium dioxide on the photostability of drug solutions was investigated using a solution consisting of a typical combination of drug solutions and $\mathrm{TiO}_{2}$; loading $100 \mathrm{mg} / \mathrm{L}$. The experiments were carried out with $100 \mathrm{~mL}$ of drug solutions. The drug solutions were stirred in dark for $30 \mathrm{~min}$ after the addition of titanium dioxide. $5 \mathrm{~mL}$ of samples of suspension were withdrawn at different intervals, immediately were centrifuged at $3000 \mathrm{rpm}$ for $10 \mathrm{~min}$ and the supernatant was filtered through syringe filter $0.45 \mu \mathrm{m}$ pore size. Changes in absorbance were monitored spectroscopically.

\section{Results and discussions}

A literature survey reveals no photostability studies for GFLX and LFLX were determined according ICH guidelines, thus the goal of this work was to study the photostability of these drugs in their bulk powders and dosage forms. In addition, this work clarifies the effect of $\mathrm{TiO}_{2}$ addition on the photostability of these drugs in their aqueous solutions.

Photostability of GFLX and LFLX in bulk powder was examined in aqueous medium. Samples were irradiated with two light doses for eight hours, Dose (I) $69 \mathrm{w} . \mathrm{m}^{-2} \cdot \mathrm{h}^{-1}$ for UV and Dose (II) 75.3 kilolux for visible. The effect of radiation on drug solutions was monitored by recording their absorption spectra at different time intervals.

The maximum absorption of GFLX and LFLX was observed at two wavelengths, 340 and $268 \mathrm{~nm}$ for GFLX and at 327 and $278 \mathrm{~nm}$ for LFLX. When aqueous solutions of GFLX and LFLX were irradiated, spectral changes were observed in their solutions. For GFLX the wavelength was shifted to 331 and 264 $\mathrm{nm}$ after irradiation, besides a remarkable decrease in its maximum absorption with increasing irradiation time (Figure 3). The maximal absorptions of LFLX at 327 and $278 \mathrm{~nm}$ were shifted to 324 and $273 \mathrm{~nm}$. Similarly, the absorption spectrum of LFLX was remarkably decreased by increasing irradiation time (Figure 4). The UV spectra recorded of these two drugs show a hypsochromic shift ranged from 2 to $9 \mathrm{~nm}$ which indicates the loss of a weak chromphoric group such as fluorine atom, thus photodeflouration occurred [20].

Therefore, the aqueous solutions of GFLX and LFLX in their bulk powder are photo-chemically unstable and their rates of photodegradation obey first order of kinetic law. By plotting ln A (Absorbance) versus time of illumination, the rate constants of photodegradation are 0.105 and $0.1191 / \mathrm{h}$ for GFLX and LFLX, respectively (Figure 3 and 4). The rate of photodegradation of LFLX is slightly greater than GFLX, this means that LFLX is more photolabile than GFLX. This may be attributed to 
the fact that high degree of flourations may result in decreasing photostability [21]. Thus LFLX (6,8-diflourinated quinolones) was found to be less stable than GFLX, 6-monoflourinated quinolones.

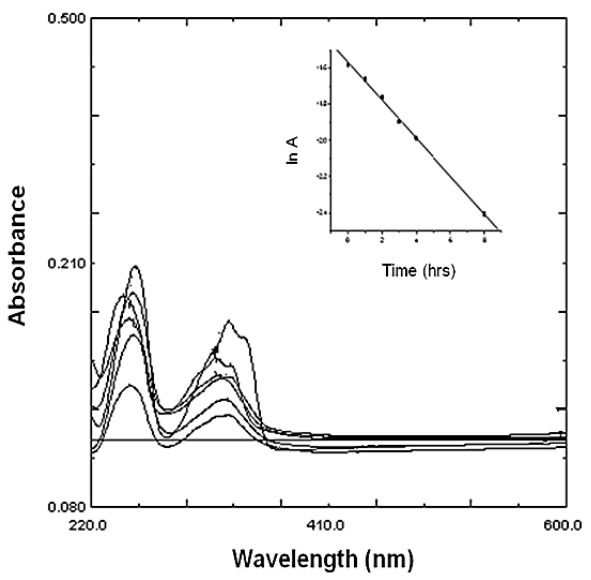

Figure 3. Change in absorption spectra of gemifloxacin solution after irradiation and determination of its rate of photodegradation.

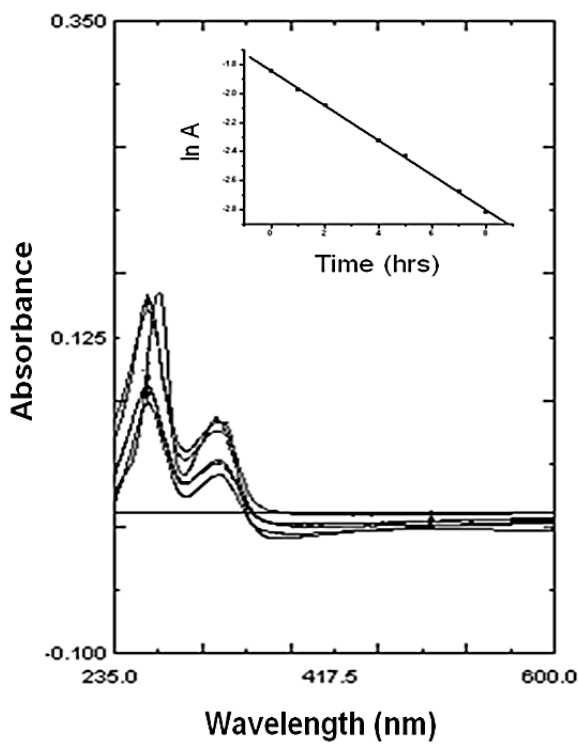

Figure 4. Change in absorption spectra of lomefloxacin solution after irradiation and determination of its rate of photodegradation.

\subsection{HPLC analysis}

On the analysis of non-irradiated and irradiated GFLX solutions by HPLC, the chromatogram corresponding to nonirradiated solution showed characteristic peak of the drug at retention time $2.932 \mathrm{~min}$ (Figure 5A), and the chromatogram of GFLX solution after irradiation exhibited four peaks which are corresponding to four degradation products with retention time at 2.547, 2.887, 3.100 and 3.369 min, respectively (Figure 5B).

The non-irradiated and irradiated LFLX solutions were also analyzed by HPLC. The chromatogram of non-irradiated solution showed only the peak of the drug at retention time 2.310 min (Figure 6A) and the chromatogram of GFLX solution after irradiation exhibited three peaks corresponding to three degradation products with retention time 2.752, 3.161 and $3.442 \mathrm{~min}$, respectively (Figure 6B).
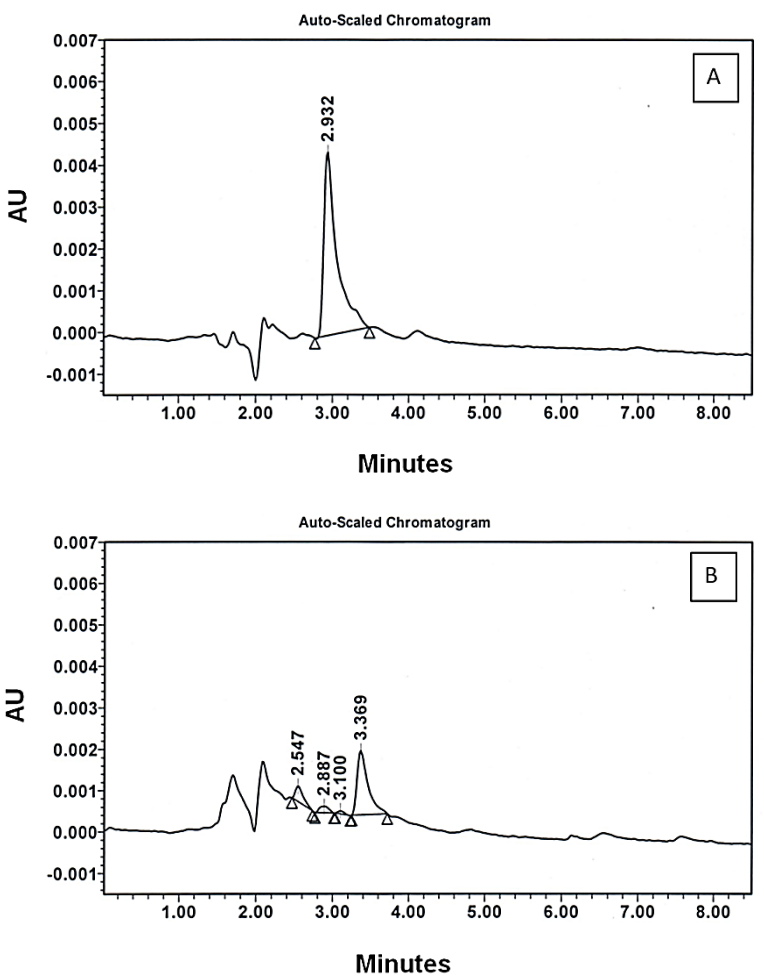

Figure 5. HPLC chromatogram of gemifloxacin (A) pre-exposure and (B) post-exposure to the illumination.
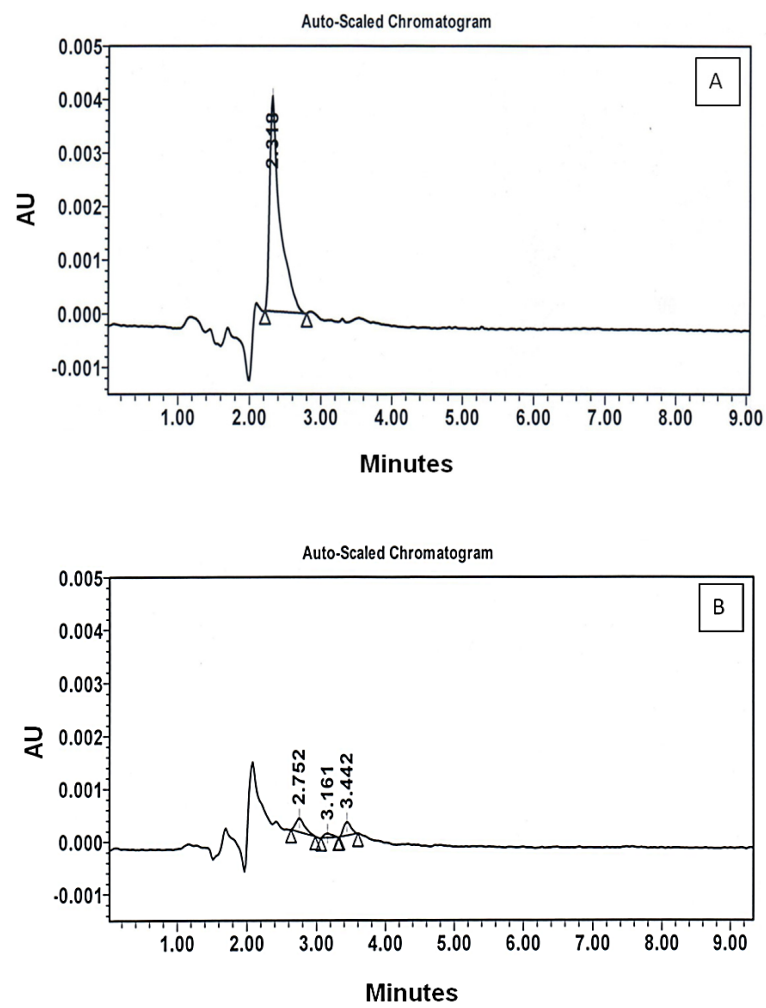

Figure 6. HPLC chromatogram of lomefloxacin (A) pre-exposure and (B) post-exposure to the illumination. 
<smiles>CCn1ccc(=O)c2ccc(N3CC(=N)C(CN)C3)nc21</smiles><smiles>CC(C)C(=O)OCCO</smiles><smiles></smiles><smiles>CO/N=C1\CN(c2ccc3c(=O)ccn(C)c3n2)CCC1CN</smiles><smiles>CC(C)C(=O)OCc1ccccc1</smiles><smiles>Cn1ccc(=O)c2ccc(N3CCC(CN)C3)nc21</smiles>

Scheme 1

\subsection{LC-MS/MS analysis}

The LC-MS/MS was used to illustrate the degradation pathway for both GFLX and LFLX. The mass spectra for GFLX solution before and after illumination were recorded. The molecular ion of GFLX before illumination was detected at $\mathrm{m} / z$ $390.5(\mathrm{M}+\mathrm{H})$ (Figure 7A). The mass spectra of GFLX solution after illumination exhibited a complete degradation of the drug solution and formation of four degradation products with molecular masses as follows: 335 (M-F, COOH), 301(M-F, $\left.\mathrm{COOH}, \mathrm{CH}_{3} \mathrm{O}\right), 294\left(\mathrm{M}-\mathrm{C}_{6} \mathrm{~N}_{3} \mathrm{OH}_{11}\right)$ and 289 (M-F, $\left.\mathrm{COOH}, \mathrm{CH}_{3} \mathrm{ON}\right)$ for Degradation 1 (Deg. 1), Degradation 2 (Deg. 2), Degradation 3 (Deg. 3) and Degradation 4 (Deg. 4), respectively (Figure 7B). The representative total ion chromatogram of GFLX solution in MRM mode after illumination was shown in (Figure 8A) and the extracted ion chromatograms prove the presence of four degradation products (Figure 8B-E), respectively. Photodegradation pathways of GFLX were proposed and illustrated in Scheme 1.

Mass spectra for LFLX solution before and after illumination were recorded. The molecular ion of LFLX spectrum before illumination (Figure $9 \mathrm{~A}$ ) was detected at $\mathrm{m} / z$ $352.5(\mathrm{M}+\mathrm{H})$. The mass spectra of LFLX solution after illumination (Figure 9B) exhibited a complete degradation for the drug solution and formation of three degradation products which displayed at 332 (M-F), 290 (M-F, COOH) and 251 (M$\mathrm{C}_{5} \mathrm{~N}_{2} \mathrm{H}_{12}$ ) for Deg. 1, Deg. 2, and Deg. 3, respectively (Figure 9B). The representative total ion chromatogram of LFLX solution in MRM mode after illumination was shown in (Figure 10A) and the extracted ion chromatograms prove the presence of three degradation products (Figure 10B-D), respectively. Different photodegradation pathways of LFLX were proposed and illustrated in Scheme 2.

\subsection{Photostability of GFLX and LFLX in their dosage form}

The photostability of GFLX and LFLX in their dosage form was also studied. Remarkable decreases in absorbance were observed as illumination time increased (Figure 11 and 12).
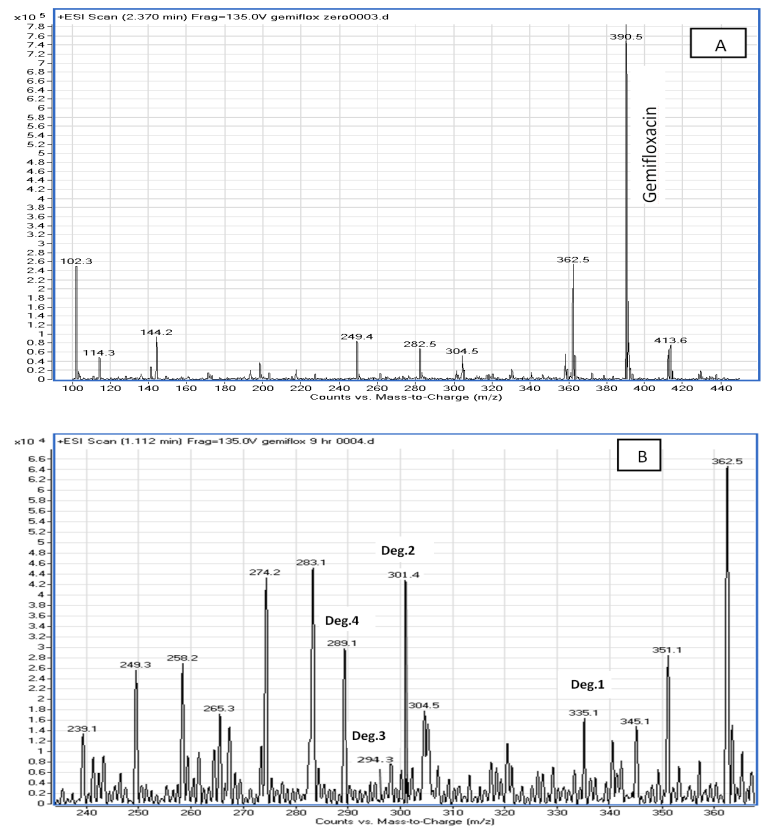

Figure 7. MS/MS spectra of gemifloxacin (A) pre-exposure and (B) postexposure to the illumination. 
Table 1. Rates of photodegradation of GFLX and LFLX in aqueous solutions.

\begin{tabular}{llll} 
Drug & $\begin{array}{l}\text { Rate of photodegradation in aqueous } \\
\text { solution, (Row material) } \mathbf{( 1 / h )}\end{array}$ & $\begin{array}{l}\text { Rate of photodegradation in aqueous } \\
\text { solution, (Tablet form) } \mathbf{( 1 / h )}\end{array}$ & $\begin{array}{l}\text { Rate of photodegradation in aqueous solution, } \\
\left.\text { (Row material in presence of TiO } \mathbf{~}_{2}\right)\end{array}$ \\
\hline (1/h)
\end{tabular}
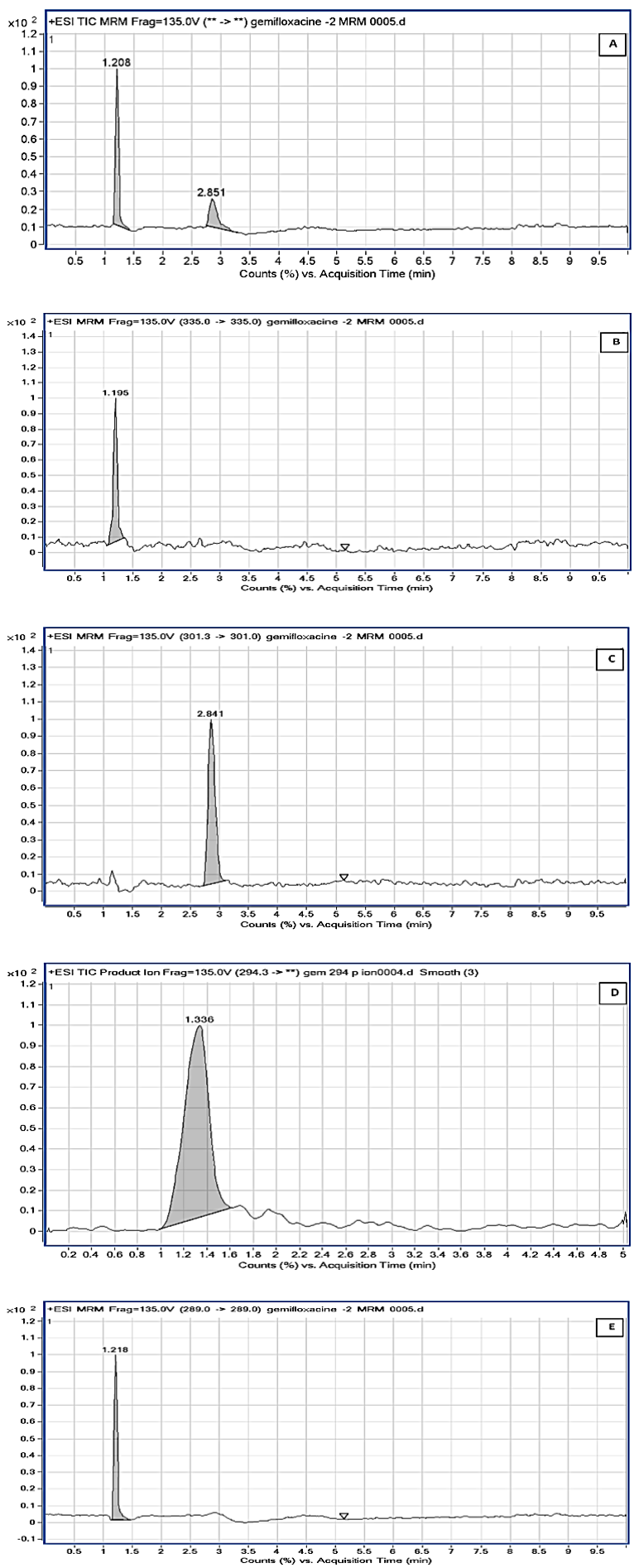

Figure 8. A representative total ion chromatogram in MRM mode of irradiated solution of gemifloxacin (A) and the extracted ion chromatogram of photodegradation products (B, C, D, and E).
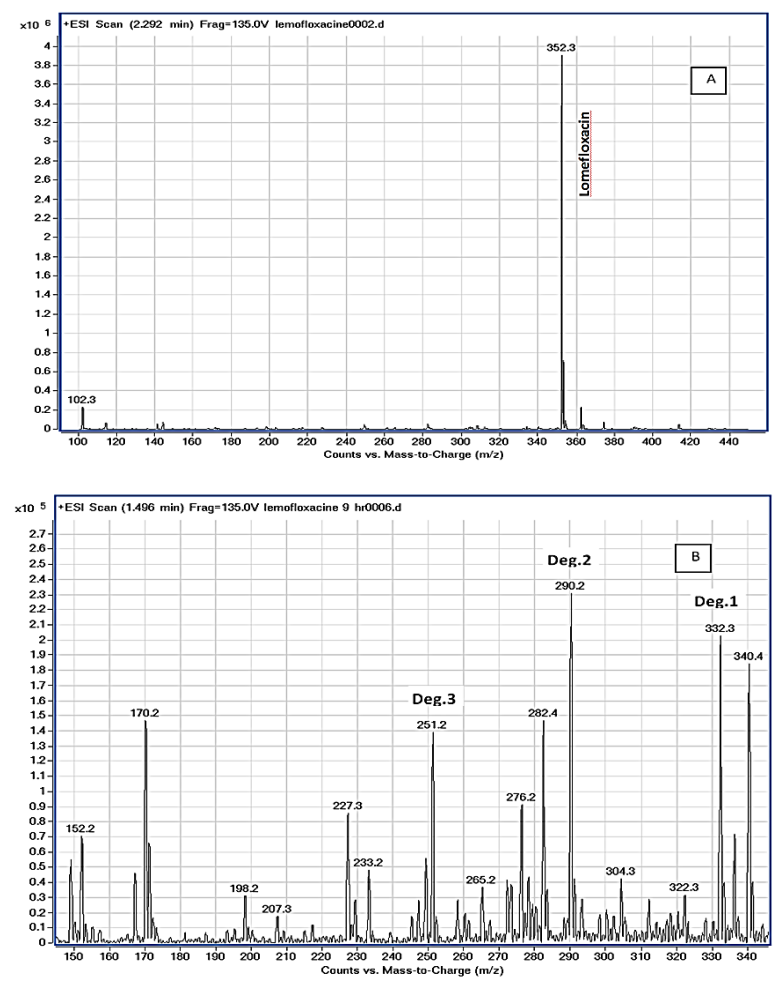

Figure 9. MS/MS spectra of lomefloxacin (A) pre-exposure and (B) postexposure to the illumination.

GFLX and LFLX in their dosage forms were also found to be photolabile and their kinetic rates of photodegradation were 0.119 1/h for GFLX and 0.157 1/h for LFLX, respectively (Table 1).

The rate of photodegradation of these drugs in their dosage form is greater than in their bulk powder. There is a decrease in the stability of GFLX and LFLX in their dosage forms, interference of one or more of the excipients might be contributing to the increase of their degradation [22]. Excipients can initiate, propagate or participate in photochemical reactions $[23,24]$. So excipients used in these drugs preparation strongly influenced the photodegradation kinetics. The stability testing for the final pharmaceutical products is very important.

\subsection{Photostability of GFLX and LFLX in presence of $\mathrm{TiO}_{2}$}

The photostability of these drugs were investigated in aqueous solutions in the presence of titanium dioxide. The rates of photodegradation of GFLX and LFLX were significantly enhanced by the addition of $\mathrm{TiO}_{2}$ (Table 1 ) in comparison with rates of photodegradation of these drugs in direct photodegradation (without $\mathrm{TiO}_{2}$ ). Photodegradation process occurred due to the adsorbing of drugs over $\mathrm{TiO}_{2}$ particles and the photodegradation is driven by injecting of an electron from excited state of drug into the conduction band of $\mathrm{TiO}_{2}$ particles which leads to the oxidation of drug molecules, also the electron of conduction band caused by moving the electrons from valence band and these electron may be used to drive another photoreactions of drug molecules in different routes. 

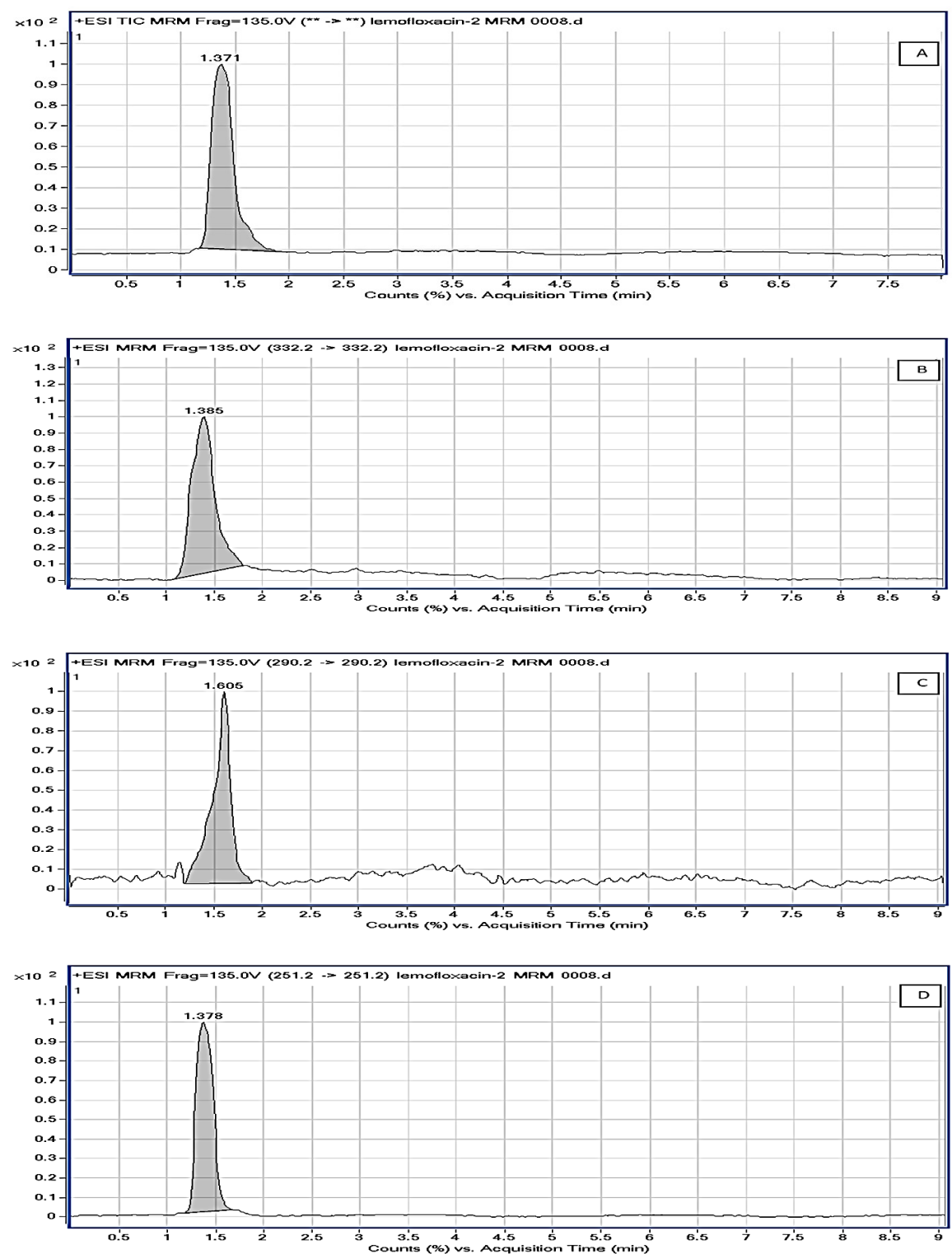

Figure 10. A representative total ion chromatogram in MRM mode of irradiated solution of lomefloxacin (A) and the extracted ion chromatogram of photodegradation products (B, C, and D).

So the presence of $\mathrm{TiO}_{2}$ causes photocatalytic activity, the mechanism of photocatalysis can be explained in details as follows equations (1-7)

$\mathrm{TiO}_{2}+\mathrm{hv} \rightarrow \mathrm{e}^{-} \mathrm{cb}+\mathrm{h}^{+} \mathrm{vb}$

$\mathrm{H}_{2} \mathrm{O}_{\mathrm{ads}}+\mathrm{h}^{+}{ }_{\mathrm{vb}} \rightarrow \mathrm{HO}^{\cdot}{ }_{\mathrm{ads}}+\mathrm{H}^{+}$

$\mathrm{O}_{2}+\mathrm{e}_{\mathrm{cb}}^{-} \rightarrow \mathrm{O}^{-}$

$\mathrm{O}_{2}+\mathrm{H}^{+} \rightarrow \mathrm{HO}_{2}$

$\mathrm{HO}_{2}+\mathrm{HO}_{2} \rightarrow \mathrm{H}_{2} \mathrm{O}_{2}$

$\mathrm{H}_{2} \mathrm{O}_{2}+\mathrm{e}^{-c b} \rightarrow \mathrm{HO}^{-}+\mathrm{HO}^{-}$

$\mathrm{D}+\mathrm{h}^{+} \mathrm{vb} \rightarrow \mathrm{D}^{+}$
Equation-1 shows the initial reaction of titanium dioxide with light, producing a hole and an electron that act as the active excited species, which then react with water and oxygen as shown in equations $2-5$. In aqueous conditions, $\mathrm{Ti}-\mathrm{OH}$ groups are abundant and are the major source of hydroxyl radicals on the $\mathrm{TiO}_{2}$ surface [25] .The downstream products of reactions with molecular oxygen are superoxide $\left(\mathrm{O}_{2} \cdot-\right.$, Equation 3$)$ and often hydroxyl radical ( $\mathrm{HO}$ - Equation 5), which can react with a nearby drug molecule. Equations 5 and 6 show the formation of hydrogen peroxide, which is known to split into two hydroxyl radicals through aqueous photolysis or to accept an electron as in Equation 6 [26].

The hole $\left(\mathrm{h}^{+}{ }_{\mathrm{vb}},\right)$ can also react directly with an adsorbed drug donor (D) as in Equation 7. The presence of titanium dioxide enhanced the rates of photodegradation. So titanium dioxide cannot be used as photoprotective agent with these drugs. 
<smiles>CCn1cc(C(=O)O)c(=O)c2cc(F)c(N3CCNC(C)C3)cc21</smiles><smiles>CC(C)(F)F</smiles><smiles>CCN1C=C(C(=O)O)C(=O)C2=CC(C(=O)O)=CN(CC)C2=C1F</smiles><smiles>CCn1ccc(=O)c2cc(F)c(N3CCNC(C)C3)cc21</smiles>

Scheme 2

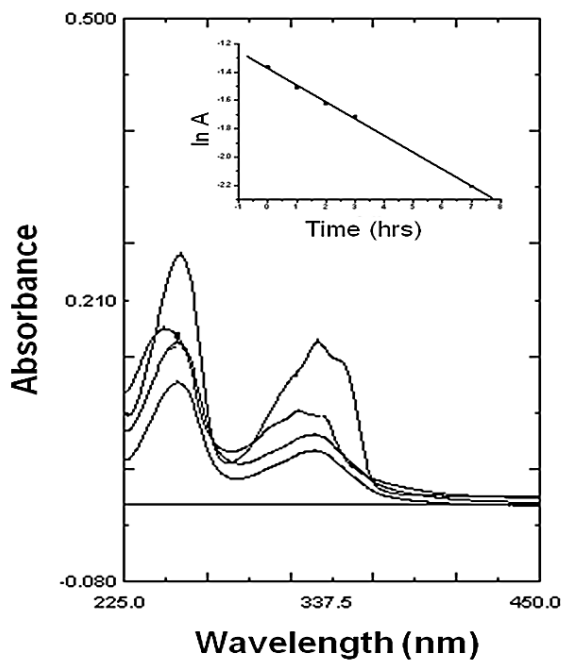

Figure 11. Change in absorption spectra in the solution of GFLX (drug product) after irradiation and determination of its rate of photodegradation.

\section{Conclusion}

The present study reveals the photolability of GFLX and LFLX in their bulk powder and their dosage forms. The rates of photodegradation of these fluoroquinolone drugs in their dosage forms are greater than in their bulk powder, thus occurring of photodegradation may be attributed to participating of the excipients used in the photochemical reaction. Titanium dioxide cannot be used as photoprotective agent with these fluoroquinolone drugs. It is necessary to avoid exposure of these drugs to light effects so special care must be taken during the preparation, manufacturing and storage of these drugs. Finally, the knowledge of drug-light interactions is a necessary prerequisite to the development of dosage forms that are stable and of good quality.

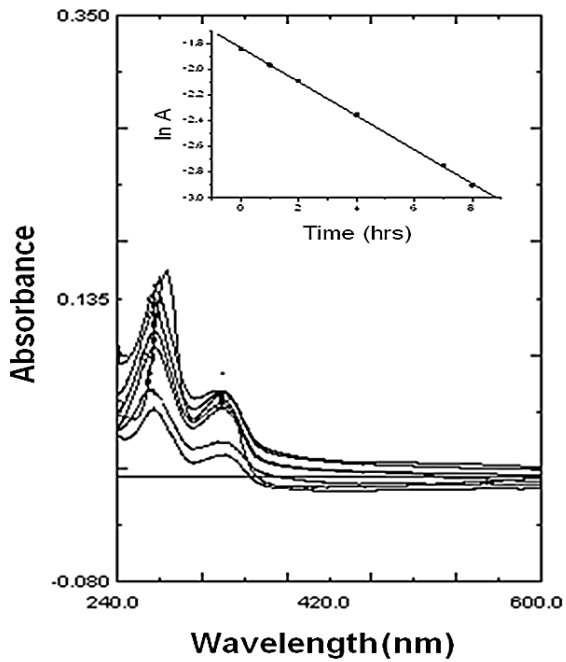

Figure 12. Change in absorption spectra in the solution of LFLX (drug product) after irradiation and determination of its rate of photodegradation.

\section{References}

[1]. Albini, A.; Fasani, E. Drugs Photochemistry and Photostability, Royal Society of Chemistry, Cambridge, 1998.

[2]. Moore, D. E. J. Pharm. Biomed. Anal. 1987, 5, 441-453.

[3]. Tonnesen, H. H. Photostability of Drugs and Drug Formulations, Taylor \& Francis, London, 1996.

[4]. Ellis, G. P; Well, G. B. Progress in Medical Chemistry, Elsevier, Amsterdam, 1990

[5]. Beijersbergen van Henegouwen, G. M. J. Adv. Drug Res. 1997, 29, 79170. 
[6]. Makinen, M.; Forbes, P. D.; Stenback, F. J. Photochem. Photobiol. B Biol. 1997, 37, 182-187.

[7]. Akthtar, M. J.; Khan, A. A.; Ahmad, I. J. Pharm. Biomed. Anal. 1999, 25, 269-275.

[8]. Selvaag, E.; Anholt, H. M. J.; Thune, P. Photodermatol. Photoimmunol. Photomed. 1996, 12, 1-12.

[9]. Domagala, J. M. J. Antimicrob. Chemother. 1994, 33, 685-706.

[10]. Sanchez, J. P.; Gogliotli, R. D.; Domagala, J. M.; Gracheck, S. J.; Huband, M. D.; Sesnie, J. A.; Cohen, M. A. Shapiro, M. A. J. Med. Chem. 1995, 38, 4478-4487.

[11]. Oliveira, H. S.; Goncalo, M.; Figueiredo, M. A. C. Photodermatol. Photoimmunol. Photomed. 2000, 16, 116-120.

[12]. Vousden, M.; Ferguson, J.; Richards, J.; Bird, N.; Allen, A. Chemotherapy 1999, 45, 512-520.

[13]. Martinez, L. J; Li, G.; Chignell, C. F. Photochem. Photobiol. 1997, 65, 599-602.

[14]. Matsumoto, M.; Kojima, K.; Nagano, H.; Matsubara, S.; Yokota, T. Antimicrob. Agents Chemother. 1992, 36, 1715-1719.

[15]. Morimura, T; Ohno, T.; Matsukura, H.; Nobuhara. Y. Chem. Pharm. Bull. 1995, 43, 1000-1004.

[16]. Man, I.; Murphy, J.; Ferguson. J. J. Antimicrob. Chemother. 1999, 43 (Suppl. B), 77-82.

[17]. Trnnesen, H. Photostability of Drugs and Drug Formulations, Taylor and Francis, London, 1996.

[18]. Sweetman S. C. Martindale: The Complete Drug Reference. $37^{\text {th }}$ ed. Pharmaceutical Press, London, England, 2012

[19]. Masahiko, M.; Kana, K.; Hiroguki, N.; Shuzo, M.; Takeshi, Y. Antimicrob. Agents Chemother. 1992, 36(8), 1715-1719.

[20]. Michael, E.; Guido, R.; Fritz, S.; Ulrike, H. Antimicrob. Agents Chemother. 1998, 42(5), 1151-1159.

[21]. Leroy, A. S.; Michael, A.; Bushra, H.; James, D. J. Pharm. Biomed. Anal. 2005, 39, 769-775.

[22]. Glass, B. D.; Vovak, C.; Brown, M. E. J. Therm. Anal. Calorim. 2004, 77, 1013-1036.

[23]. Tonnesen, H. Int. J. Pharm. 2001, 225, 1-4.

[24]. Reed, R. A.; Harmon, P.; Manas, D.; Wasylaschuk, W.; Galli, C. , Biddell, R.; Bergquist, P. A.; Hunke, W.; Templeton, A. C.; Ip , D. J. Pharm. Sci. Technol. 2003, 57, 351-368. [25]. Li, X.; Cubbage, J. W.; Tetzlaff, T. A.; Jenks, W. S. J. Org. Chem. 1999, 64,
8509-8524.

[26]. Li, X.; Cubbage, J. W.; Jenks, W. S. J. Photochem. Photobiol. A 2001, 143, 69-85. 